\title{
P065: Vancomycin resistant enterococci among patient in Kuala Lumpur Hospital, Malaysia: the occurence and its associated risk factors
}

\author{
R Ibrahim ${ }^{1 *}$, N Ahmad², MN Aziz ${ }^{3}$ \\ From 2nd International Conference on Prevention and Infection Control (ICPIC 2013) \\ Geneva, Switzerland. 25-28 June 2013
}

\begin{abstract}
Introduction
Vancomycin-resistant enterococci (VRE) are increasing in prevalence at many institutions, especially among patients with co-morbidity conditions that associated with frequent hospitalisation. It is important to determine the risk factors for this resistance microorganism as it will guide the clinician for appropriate antimicrobial therapy and infection control measures.
\end{abstract}

\section{Objectives}

The descriptive, cross sectional study was carried out to determine the prevalence and risk factors for vancomycin resistant enterococci in Kuala Lumpur Hospital (HKL), Malaysia.

\section{Methods}

For 12 months period, antimicrobial susceptibility testing for enterococci species were performed using disk diffusion method. E-test for vancomycin was proceed for the isolates that exhibit resistance to vancomycin by disk diffusion method. To identify the risk factors, a questionnaire was completed for all studied patients and the data were analysed using chi square and multivariate logistic regression.

\section{Results}

The prevalence of VRE among patients in Kuala Lumpur Hospital was $1 \%$. In chi square analysis, vancomycin usage ( $\mathrm{p}=0.000$, RR, 34.615; 95\% CI, 5.796-206.723) showed significance risk factor. In multivariate logistic regression analysis, prolonged hospitalization $(\mathrm{p}=0.040, \mathrm{R}, \mathrm{80.194}$; $95 \% \mathrm{CI}, 1.212-5304.5)$ and vancomycin use ( $\mathrm{p}=0.009, \mathrm{RR}$,
18.376; 95\% CI, 2.143-165.3) were associated with potential VRE.

\section{Conclusion}

The findings of this study will serve as an alert to the clinicians of the emergence of infections by VRE and it will encourage the implemention of appropriate infection control measures and judicious use of vancomycin in order to prevent further rise in VRE prevalence.

\section{Disclosure of interest}

None declared.

\section{Author details}

${ }^{1}$ Microbiology, Cyberjaya University College of Medical Sciences, Cyberjaya, Malaysia, Selangor. ${ }^{2}$ Microbiology, Institute of Medical Research, Kuala Lumpur. ${ }^{3}$ Microbiology, Kuala Lumpur Hospital, KL, Malaysia.

Published: 20 June 2013

\section{References}

1. European Antimicrobial Resistance Surveillance System: Susceptibility results for E. faecium isolates in 2006., http://www.rivm.nl/earss/database/ [accessed 29 May 2007

2. Mehrad Asharian, Rahim Afkhamzadeh, Ahmad Monabbati, Florian Daxboeck, Ojan Assadian: Risk factor for rectal colonization with vancomycin-resistant enterococci in Shiraz, Iran. Int. Society for Infectious Diseases 2008, 12:171-175.

3. Zhannel GG, Laing NM, Nichol KA, et al: Antibiotic activity against urinary tract infection (UTI) isolates of vancomycin-resistant enterococci. Journal of Antimicrobial Chemotherapy 2003, 52:382-388.

doi:10.1186/2047-2994-2-S1-P65

Cite this article as: Ibrahim et al:: P065: Vancomycin resistant enterococci among patient in Kuala Lumpur Hospital, Malaysia: the occurence and its associated risk factors. Antimicrobial Resistance and Infection Control 2013 2(Suppl 1):P65.

'Microbiology, Cyberjaya University College of Medical Sciences, Cyberjaya, Malaysia, Selangor

Full list of author information is available at the end of the article

๑ 2013 lbrahim et al; licensee BioMed Central Ltd. This is an Open Access article distributed under the terms of the Creative Commons 